Barty Lyons FFarCsi, Nuala Cregg FFaRCSI, Frances Conway FFARCSI, William Casey FFARCSI, Patrick Doherty fFarcsi, Kevin P. Moore fFarcsi

\title{
Premedication for ambulatory surgery in preschool children: a comparison of oral midazolam and rectal thiopentone
}

Seventy five ASA 1 and 2 children, aged between six months and five years were randomized to receive oral midazolam 0.5 $\mathrm{mg} \cdot \mathrm{kg}^{-1}$, rectal thiopentone $35 \mathrm{mg} \cdot \mathrm{kg}^{-1}$ or no premedication to compare the safety and efficacy of, and parental attitudes to, both premedicants. Cardio-respiratory variables were recorded from the time of premedication to awakening from anaesthesia. In addition, anxiety and sedation scores and patients' acceptance of both premedicant and mask at induction, were all recorded using four-point rating scales. Times to recovery and discharge, and parental satisfaction with the premedication their child had received were also recorded. Children receiving rectal thiopentone had higher sedation scores and were more accepting of the mask than were the other two groups $(P<0.001)$. Their acceptance of the premedication was similar to that of the midazolam group. Times to spontaneous eye opening and discharge were longer in the thiopentone group $(P<0.005)$. Parental preoperative satisfaction rating was higher for thiopentone, but not midazolam, than no premedication $(P<0.05)$. When asked their premedication preferences for subsequent general anaesthetics, a higher proportion of parents whose children were not premedicated requested an alternative regimen $(P<0.01)$. In conclusion the study found that premedication with rectal thiopentone provided superior induction characteristics to oral midazolam, but with a longer recovery period.

\section{Key words}

PREMEDICATION: midazolam, thiopentone;

ANAESTHESIA: paediatric;

ANAESTHESIA TECHNIQUES: general, inhalation.

From the Department of Anaesthesia, Our Lady's Hospital for Sick Children, Crumlin, Dublin 12, Ireland.

Address correspondence to: Dr. B. Lyons, Department of Anaesthesia, Our Lady's Hospital for Sick Children, Crumlin, Dublin 12, Ireland.

Accepted for publication 10th February, 1995.
Cette étude vise à comparer l'efficacité et la sécurité de deux prémédications et l'opinion des parents sur celles-ci. Soixantequinze enfants ASA 1 et 2 âgés de six mois à cinq ans sont répartis au hasard pour recevoir une prémédication soit au midazolam, $0,5 \mathrm{mg} \cdot \mathrm{kg}^{-1}$, per as ou au thiopentone rectal, 35 $\mathrm{mg} \cdot \mathrm{kg}^{-1}$, soit aucune prémédication. Les paramètres cardiorespiratoires sont enregistrés à partir du moment de la prémédication jusqu'au réveil. En outre, les scores de sédation et d'anxiété et d'acceptation des dewx prémédications par les parents ainsi que du masque à linduction par l'enfant sont enregistrés sur une échelle à quatre niveaux. On enregistre aussi le moment du réveil et du congé ainsi que la satisfaction des parents vis-à-vis la prémédication que l'enfant a reçue. Les enfants qui reçoivent le thiopentone rectal ont un score de sédation plus élevé et acceptent plus facilement le masque que les deux autres groupes $(P<0.001)$. Leur acceptation de la prémédication est identique à celle du groupe midazolam. Lintervalle mesuré jusqu'à l'ouverture des yeux et jusqu'au congé est plus long dans le groupe thiopentone $(P<0.005)$. A la période pré-opératoire, la cote de satisfaction des parents est plus élevée pour le thiopentone, mais non pour le midazolam, que pour l'absence de prémédication $(P<0.05)$. Lorsqu'on leur demande quelle serait leur préférence pour une anesthésie générale subséquente, une plus grande proportion de parents dont les enfants n'ont pas reçu de prémédication, répondent qu'tls préfereraient une autre méthode $(P<0.01)$. Pour conclure, cette étude révèle que la prémédication au thiopentone rectal produit des caractéristiques d'induction supérieurs au midazolam oral, mais quelle prolonge la période de récupération.

Although daycare surgery is perceived to be less emotionally disturbing to a child than an operation requiring a more protracted hospital admission, ${ }^{1,2}$ anaesthetic induction for ambulatory procedures is still a potentially distressing experience for the paediatric patient. The screaming child requiring parental or nursing constraint 
to permit induction of anaesthesia may suffer psychological sequelae, ${ }^{3,4}$ and is likely to view future hospitalisation with a mixture of profound suspicion and terror. This struggle also has an emotional impact on parents present in the anaesthetic room. ${ }^{5}$

The preschool child is the least likely to cooperate with induction of anaesthesia (regardless of sex, race or technique), ${ }^{6-8}$ and the most at risk to experience a negative psychological aftermath. ${ }^{2}$ Despite intensive prehospital preparation children in this age group may still undergo stormy inductions. ${ }^{6,7}$ Thus, there is a clear need for pharmacological supplementation to prepare the anxious and unpredictable child.

The large quantity of literature published relating to premedication for children is indicative that the search for the "ideal" agent has not yet yielded a universally satisfactory drug. Rectal thiopentone is a sedative agent that has been used for many years, and is safe and effective. ${ }^{16-20}$ Oral midazolam has been advocated more recently to provide excellent anxiolysis and sedation for paediatric daycase surgery, ${ }^{9-11}$ and may be more suitable for outpatient procedures because of its shorter duration of action. ${ }^{12,13}$ The aim of this study was to compare these two premedicants, with different routes of delivery, with no premedication, and to assess anaesthetist and parental satisfaction with each.

\section{Methods}

The study was approved by the Hospital Ethics Committee and written parental consent was obtained in each case. Seventy-eight ASA 1 and 2 children, aged between six months and five years, undergoing elective daycase procedures were enrolled. Operations included minor lower abdominal, urological, plastic and orthopaedic procedures. Exclusion criteria included a previous general anaesthetic, current anti-convulsant or sedative medication, known sensitivity to barbiturates or benzodiazepines, airway problems, the presence of upper or lower gastrointestinal pathology, or severe nappy rash. The children were randomized to one of three groups. Group 1 received midazolam $0.5 \mathrm{mg} \cdot \mathrm{kg}^{-1}\left(5 \mathrm{mg} \cdot \mathrm{ml}^{-1}\right.$ preparation) po diluted with twice the volume of orange flavoured syrup $(\mathrm{pH}=4.3)$ to disguise the bitter taste. Those in Group 2 received sodium thiopentone $35 \mathrm{mg} \cdot \mathrm{kg}^{-1} \mathrm{pr}$, and those in Group 3 received no premedication. Acceptance of the premedicant was recorded on a four-point scale similar to that used by Feld et al. to assess mask acceptance ${ }^{9}$ ( $1=$ combative/screaming; $2=$ crying but easily reassured; $3=$ occasional sobbing $/$ mostly calm; $4=$ peaceful). No attempt was made to provide placebos or dummy drug administration, so parents could comment on both the route of drug delivery and the effectiveness of the premedication that their child received. All premedicants were administered approximately $30 \mathrm{~min}$ before the expected time of induction of anaesthesia.

Heart and respiratory rates, and oxygen saturation were measured every five minutes, and sedation and anxiety levels scored by a blinded anaesthetist every ten minutes from administration of the premedicant to induction. Sedation was measured on a four-point scale $(1=$ alert $/$ active; $2=$ awake $/$ calm; $3=$ drowsy but responds to verbal $/$ tactile stimuli; $4=$ asleep). ${ }^{10}$ Anxiolysis was also measured on a four-point scale $(1=$ tearful/combative; $2=$ anxious but easily reassured; $3=$ calm; $4=$ asleep). ${ }^{10}$ Adverse events including apnoea or airway obstruction were also recorded. All parents were invited to come to theatre with their child and be present during the induction.

In the anaesthetic room, anxiety and sedation scores were recorded prior to induction of anaesthesia which was by inhalation of oxygen, nitrous oxide and halothane. The anaesthetist was blinded to the premedication. Mask acceptance was recorded by the anaesthetist using the same scale that was used for premedication acceptance. All patients were allowed to breathe spontaneously via a facemask or laryngeal mask airway during surgery, with the inspired halothane concentration titrated to maintain haemodynamic variables within $20 \%$ of preoperative levels. Analgesia was provided by field blocks or wound infiltration with bupivacaine $0.5 \%$. No opioids or other sedatives were administered.

Following surgery patients were transferred to the recovery room where heart rate and respiratory rate were recorded every five minutes, and oxygen saturation monitored continuously until discharge to the day-ward. The level of consciousness $(1=$ awake/active; $2=\mathrm{calm} ; 3$ $=$ rousable to tactile or verbal stimuli; $4=$ asleep) ${ }^{10}$ and agitation $(1=$ peaceful; $2=$ occasional sobbing $/$ mostly calm; $3=$ crying but settles with reassurance; $4=$ thrashing around, crying and requiring restraint) were both recorded every five minutes for fifteen minutes, and every quarter hour thereafter during the child's stay in the recovery room. The time to spontaneous eye opening was also recorded.

When children were awake they were discharged to the day unit where they were reunited with their parents. When the children were tolerating oral fluids, were painfree and had passed urine they were allowed home. Before discharge from the hospital, parents were asked to fill in a short questionnaire regarding their attitudes and satisfaction with the premedicant their child had been given. They were asked to rate their pre- and postoperative experiences on a three-point scale $(1=$ excellent; $2=$ acceptable; $3=$ unacceptable/unpleasant). ${ }^{9}$ Parents were also asked to indicate whether they would like their child to receive the same or a different premedicant should their child require anaesthesia in the future. 
TABLE I Demographic data, mean (SD)

\begin{tabular}{llll}
\hline & $\begin{array}{l}\text { Midazolam } \\
n=26\end{array}$ & $\begin{array}{l}\text { Thiopentone } \\
n=25\end{array}$ & $\begin{array}{l}\text { No premed. } \\
n=24\end{array}$ \\
\hline Age (mo) & $37.6(14.24)$ & $28.5(14.48)$ & $32.9(15.18)$ \\
Sex (M/F) & $15 / 11$ & $14 / 11$ & $22 / 2^{*}$ \\
Weight (kg) & $15.2(2.89)$ & $13.8(2.48)$ & $13.8(3.14)$ \\
Anaesthetic time (min) & $26.7(13.22)$ & $36.0(17.47)$ & $34.1(24.97)$ \\
\hline
\end{tabular}

$* P<0.01$.

Power analysis indicated that by allowing a successful level for mask acceptance of $60 \%$ for midazolam ${ }^{10}$ and an estimated $90 \%$ for thiopentone, then using an $\alpha$ of 0.05 and a $\beta$ of 0.2 , a minimum of 23 patients per group were required. Results were analyzed using analysis of variance (ANOVA) for parametric data, Chi square test for categorical data, and Kruskal-Wallis test and Spearman Rank Order Correlation for non-parametric data. Results were considered significant at $P<0.05$.

\section{Results}

\section{Demographic data}

Age, weight and duration of anaesthesia were similar in the three groups (Table I). However, there were fewer girls in the group receiving no premedication $(P<0.01)$.

\section{Acceptability of premedication}

Three patients rejected their premedication (midazolam $=2$; thiopentone $=1$ ). They were omitted from further assessment. There was no difference between patient acceptance of midazolam or thiopentone (Chi square $=$ 4.95; $P=0.176)$.

\section{Preoperative assessment}

The time from administration of the premedicant to induction was similar in both the midazolam (40 $\mathrm{min} \pm$ $14.3)$ and thiopentone $(37.6 \pm 17.3)$ groups.

Most patients $(88 \%)$ who received thiopentone were asleep at ten minutes, and $92 \%$ were asleep and $4 \%$ very drowsy on arrival in the anaesthetic room. In the midazolam group $50 \%$ were calm and $11.5 \%$ drowsy or asleep at ten minutes, and $69 \%$ calm, $15.4 \%$ drowsy and $3.8 \%$ asleep on arrival in the theatre. All 24 patients in the no premedication group were awake and alert on arrival in the theatre. Anxiety scores prior to premedication were similar in all groups. Anxiety scores on arrival in theatre are shown in Figure 1.

Children in the thiopentone group had the greatest decreases in both heart rate and respiratory rate $(P<0.005$; Table II), but these were clinically unimportant. The changes in oxygen saturation were slight and similar in all three groups.

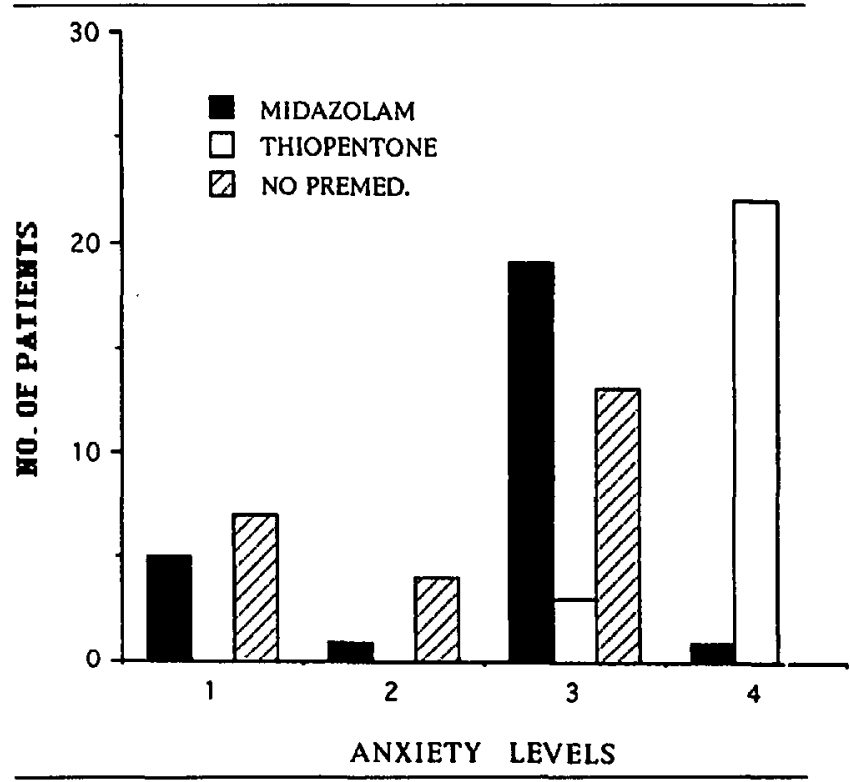

FIGURE 1 Anxiety score of children on arrival into theatre, prior to induction ( $1=$ tearful/combative; 2 = anxious but easily reassured; $3=$ calm; $4=$ asleep). Group receiving no premedication had lower scores than other two groups $(P<0.05)$.

TABLE II Greatest changes in heart rate (beats ' $\mathrm{min}^{-1}$ ), respiratory rate (breaths $\cdot \mathrm{min}^{-1}$ ) and oxygen saturation (\%); mean (SD). Changes in thiopentone group were significant when compared with either no premedication or midazolam groups

\begin{tabular}{llll}
\hline & $\begin{array}{l}\text { Midazolam } \\
n=26\end{array}$ & $\begin{array}{l}\text { Thiopentone } \\
n=25\end{array}$ & $\begin{array}{l}\text { No premed. } \\
n=24\end{array}$ \\
\hline Change in & & & \\
Heart rate & $-5.8(13.1)$ & $-14.4(13.6)^{*}$ & $+1.88(10.2)$ \\
Resp. rate & $-1.8(3.7)$ & $-5.5(3.5)^{*}$ & $+1.04(3.1)$ \\
$\mathrm{SaO}_{2}$ & $-0.19(0.8)$ & $-0.62(1.3)$ & $-0.60(0.9)$ \\
\hline
\end{tabular}

$* P<0.005$.

\section{Mask acceptance}

Mask acceptance was better in patients who received thiopentone than in either of the other two groups $(P<$ 0.001) (Figure 2). Acceptance by patients who received midazolam was no better than those who did not receive premedication. When patients who were asleep were omitted from analysis, there was no correlation between anxiety behaviour on entry into the anaesthetic room and mask acceptance $(P=0.5)$.

\section{Postoperative assessment}

The time to spontaneous eye opening was delayed in the thiopentone group (50.2 $\pm 18 \mathrm{~min})$ when compared with the midazolam group $(33 \pm 16.5 \mathrm{~min})(P<0.005)$ and with the no premedication group $(22.4 \pm 11.41 \mathrm{~min})(P$ $<0.001$ ). 


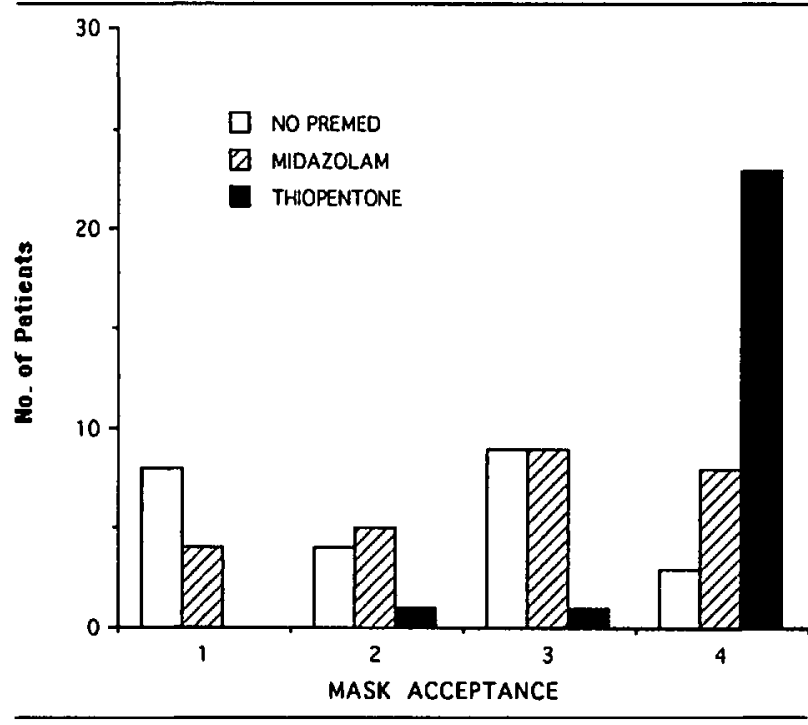

FIGURE 2 Mask acceptance by patients ( 1 = combative/screaming, $2=$ crying but easily reassured; $3=$ occasionally sobbing $/$ mostly calm; $4=$ peaceful). Mask acceptance in thiopentone group significantly better $(P<0.0001)$

Similarly, the time to discharge was shorter in the groups who received either no premedication (104.3 \pm $32.3 \mathrm{~min})$ or midazolam $(105.5 \pm 30 \mathrm{~min})$ than in the thiopentone group $(151.9 \pm 63.2 \mathrm{~min})(P<0.005)$.

Eighty-eight percent of all patients were calm and content on the dayward following surgery. Three patients from each group remained upset on the ward, despite the absence of pain and the presence of their parents. This distress was not related to the difficulty of induction.

\section{Parental impressions}

All parents were invited to be present during the induction of their child. Twenty-four out of twenty-five parents whose children had received rectal thiopentone declined to enter theatre on the basis that their child was already asleep. All other parents attended.

The preoperative satisfaction scores of parents present in the anaesthetic room correlated significantly with their child's behaviour at induction of anaesthesia $(P=0.002)$, while the satisfaction scores of the parents of the thiopentone group, who did not enter the theatre complex, correlated with their child's depth of sedation prior to transfer to the anaesthetic room $(P=0.01)$. Parents whose children were not given premedication had a lower satisfaction rating than the other two groups of parents $(P=0.017$; Table III).

Parental happiness following their child's return from theatre did not correlate with any single factor. Six parents found the postoperative period to be unpleasant and unacceptable (midazolam $(n=1)$ and no premedication
TABLE III Pre- and postoperative parental satisfaction scores

\begin{tabular}{cccc}
\hline & $\begin{array}{l}\text { Midazolam } \\
n=26\end{array}$ & $\begin{array}{l}\text { Thiopentone } \\
n=25\end{array}$ & $\begin{array}{l}\text { No premed. } \\
n=24\end{array}$ \\
\hline $\begin{array}{l}\text { Satisfaction score } \\
\text { Pre-op } 1\end{array}$ & 17 & 22 & $12^{*}$ \\
2 & 4 & 3 & 3 \\
3 & 5 & 0 & 9 \\
& & & \\
Post-op 1 & 20 & 19 & 11 \\
2 & 5 & 4 & 10 \\
3 & 1 & 2 & 3 \\
\hline
\end{tabular}

${ }^{*} P<0.05$ vs children receiving thiopentone.

group $(n=3)$ : "children crying and completely inconsolable on ward"; thiopentone $(n=2)$ : "delayed recovery and discharge." Scores were similar in all three groups.

Most, $62.5 \%$, of those parents whose children were not premedicated indicated that they would prefer their child to receive premedication for future anaesthetics ( $P$ $<0.01$ vs either of the other two groups). When asked whether they would rather an oral or a rectal route of administration $88 \%$ of parents expressed no preference, and $12 \%$ preferred oral administration.

\section{Discussion}

Daycase surgery for children was described as early as the turn of this century. ${ }^{14}$ Its popularity has increased greatly in recent times for medico-economic reasons. Because of fears of delayed discharge there has been a tendency to avoid pharmacological premedication in daycare patients. Thus, children scheduled for ambulatory procedures undergo a similar anaesthetic induction to their inpatient counterparts, but without the same degree of preoperative preparation. The purpose of premedication is to provide sufficient sedation and anxiolysis to allow a smooth and atraumatic anaesthetic induction. Preschool children may be too young to accept explanation of succeeding events and, therefore, will frequently refuse to cooperate during induction. The resulting unhappy experience suggests that it would be both rational and humane to premedicate these patients. That a greater number of parents whose children received either thiopentone $(84 \%)$ or midazolam $(73 \%)$, would opt for the same premedicant regimen for a subsequent general anaesthetic, when compared with parents whose children were not premedicated $(32 \%)$, indicates that parents are in favour of pharmacological premedication for their preschool children.

Recent reports of midazolam have been encouraging. McMillan et al. in their study involving one- to six-yearold children found that $0.5 \mathrm{mg} \cdot \mathrm{kg}^{-1}$ of midazolam po provided excellent anxiolysis at the time of separation 
from parents $(90 \%)$, and at induction $(60 \%) .{ }^{10}$ Our results for midazolam were similar, with $65 \%$ of these patients scoring 3 or 4 for mask acceptance. However, this was no better than the group who did not receive premedication (50\%). It is controversial whether $0.5 \mathrm{mg} \cdot \mathrm{kg}^{-1}$ is the optimal dose of midazolam for premedication in children. A previous study has shown that increasing the dose to 0.75 or $1 \mathrm{mg} \cdot \mathrm{kg}^{-1}$ results in an increased number of side effects while failing to improve sedation and anxiolysis. ${ }^{10}$ Feld et al. found that, when compared with 0.5 $\mathrm{mg} \cdot \mathrm{kg}^{-1}$, a dose of $0.75 \mathrm{mg} \cdot \mathrm{kg}^{-1}$ increased the level of sedation at $30 \mathrm{~min}$, and reduced postoperative recall. ${ }^{9}$

Rectal thiopentone possesses several attributes that make it a suitable premedicant. Administration was as well tolerated as oral midazolam, probably due, in part, to the bitter taste of midazolam. It allowed children to drift off to sleep gradually in the presence of his/her parents in a pleasant and relaxed fashion. When the time came for the child to go to the operating room the parents deemed it unnecessary to accompany their child thereby avoiding a stressful encounter. Vessey $e t$ al. found that "seeing the child upset prior to induction" and "watching the child go limp" were two of the three most distressing events for parents during induction of anaesthesia. ${ }^{5}$ Rectal premedication eliminated these ordeals for the parents. Induction of anaesthesia was easily achieved and without any struggle.

Rectal barbiturates have been used to sedate paediatric patients for a number of years. Although side effects such as hypotension, bronchospasm and laryngospasm have been reported, ${ }^{15}$ several reports testify to their safety. ${ }^{16-20}$ In this study monitored cardio-respiratory variables remained above acceptable levels following administration of rectal thiopentone. However, we do advocate that all children should be closely observed by trained personnel to prevent potential airway problems after administration of sedative drugs.

In theory, differing bioavailability of rectally administered substances may occur because of individual variation in rectal $\mathbf{p H} .{ }^{21}$ Clinically this is not a problem. O'Brien et al. reported a $20 \%$ sedation failure rate, ${ }^{17}$ but used a lower dose $\left(25 \mathrm{mg} \cdot \mathrm{kg}^{-1}\right)$ as sole sedation before suturing of lacerations. Almost all, $96 \%$, of our patients were asleep or drowsy on arrival in the anaesthetic room. This predictability makes it a useful agent in an unpredictable population.

It would be gratifying to sedate only those children who were likely to undergo difficult inductions. Unfortunately neither anxiety behaviour in the day unit nor in the anaesthetic room proved to be reliable indicators of conduct at induction. More sophisticated psychometric tests may have been more sensitive predictors, but are not practically applicable during a busy operating list.
Obviously, from the point of view of the anaesthetist, it is easier to induce anaesthesia in a heavily sedated child than in one who vehemently resists the application of a face mask.

Cultural and individual factors may influence the aesthetic acceptability of rectally administered compounds. The rectal route of premedication has been described as being possibly the least disturbing method of sedating children, since it involves neither painful injections nor swallowing of suspicious potions. ${ }^{22}$ Among our population, $88 \%$ of parents expressed no preference for either the oral or rectal route.

The main problem encountered with the use of rectal thiopentone is that of delayed discharge. The average duration of postoperative stay was $50 \%$ more for the thiopentone group than for either of the other two groups. This was solely due to sedation, and not to any other confounding variable such as vomiting or pain. Although all patients were able to be discharged home on the day of surgery, $12 \%$ of parents were unhappy with the duration of sedation. Prolonged sedation has benefits since it permits even lengthy delays in the running of a list. However, a protracted hospital stay, even by a few hours, is an undesirable consequence. Rectal thiopentone, 25 $\mathrm{mg} \cdot \mathrm{kg}^{-1}$, has been shown to provide a mean duration of sedation of $2.75 \mathrm{hr} .{ }^{17}$ Reduction of our premedication dose from $35 \mathrm{mg} \cdot \mathrm{kg}^{-1}$ may enhance recovery without a deleterious effect on preoperative sedation.

In conclusion, this study demonstrated that rectal thiopentone provides safe sedation and leads to superior anaesthesia induction characteristics than does oral midazolam in the doses used. However, the increase in hospital stay, by up to $50 \%$, is a major drawback of this technique. It is possible that adjustment of the dose of each drug, thiopentone downwards and midazolam upwards, may lead to a suitable efficacy and duration of stay in each case. Despite the individual disadvantages of each drug, the majority of parents whose children received either premedicant were satisfied.

\section{References}

1 Scaife JM, Cambell I. A comparison of the outcome of day-care and inpatient treatment of paediatric surgical cases. J Child Psychol Psychiatry 1988; 29: 185-98.

2 Meursing $A E E$. Psychological effects of anaesthesia in children. Current Opinion in Anaesthesiology 1989; 2: 335-8.

3 Bothe A, Galdston $R$. The child's loss of consciousness: a psychiatric view of pediatric anesthesia. Pediatrics 1972; 50: 252-63.

4 Meyers EF, Muravchik $S$. Anesthesia induction technics in pediatric patients: a controlled study of behavioral consequences. Anesth Analg 1977; 56: 538-42. 
5 Vessey JA, Bogetz MS, Caserza CL, Liu KR, Cassidy MD. Parental upset associated with participation in induction of anaesthesia in children. Can J Anaesth 1994: 41: 276-80.

6 Rosen DA, Rosen KR, Hannallah RS. Anaesthesia induction in children. Ability to predict cooperation. Paediatric Anaesthesia 1993; 3: 365-70.

7 Visintainer MA, Wolfer JA. Psychological preparation for surgical pediatric patients: the effect on children's and parents' stress responses and adjustment. Pediatrics 1975; 56: 187-202.

8 Stingle SF, Cook $H$. Age and sex differences in the cooperative and noncooperative behavior of pairs of American children. J Psychol 1985; 199: 335-45.

9 Feld $L H$, Negus $J B$, White PF. Oral midazolam preanesthetic medication in pediatric outpatients. Anesthesiology 1990; 73: 831-4.

10 McMillan CO, Spahr-Schopfer IA, Sikich N, Hartley E, Lerman J. Premedication of children with oral midazolam. Can J Anaesth 1992; 39: 545-50.

11 Parnis SJ, Foate JA, van der Walt JH, Short T, Crowe CE. Oral midazolam is an effective premedication for children having day-stay anaesthesia. Anaesth Intensive Care 1992; 20: 9-14.

12 Coté CJ. Sedation for the pediatric patient. Pediatr Clin North Am 1994; 41: 31-58.

13 De Boer AG, De Leede LGJ, Breimer DD. Drug absorption by sublingual and rectal routes. $\mathrm{Br} J$ Anaesth 1984; 56: 69-80.

14 Nicoll JH. The surgery of infancy. BMJ 1909; 2: 753-4.

15 Rectal Thiopentone Drug Information. Abbot Laboratories 1980.

16 Schreuder M, Basenberg AT, Murray WB. Anaesthesia without tears. S Afr Med J 1992; 81: 317-8.

17 O'Brien JF, Falk JL, Carey BE, Malone LC. Rectal thiopental compared with intramuscular meperidine, promethazine, and chlorpromazine for pediatric sedation. Ann Emerg Med 1991; 20: 644-7.

18 Burckart GJ, White TJ III, Siegle RL, Jabbour JT, Ramey $D R$. Rectal thiopental versus an intramuscular cocktail for sedating children before computerized tomography. Am J Hosp Pharm 1980; 37: 222-4.

19 Lynn AM, Morray JP, Furman EB. Short-acting barbiturate sedation: effect on arterial $\mathrm{pH}$ and $\mathrm{PaCO}_{2}$. Can J Anaesth 1988; 35: 76-9.

20 Daniels AL, Coté CJ, Polaner DM. Continuous oxygen saturation monitoring following rectal methohexitone induction in paediatric patients. Can J Anaesth 1992; 39: 27-30.

21 Jantzen J-PAH, Tzanoa I, Witton PK, Klein AM. Rectal pH in children. Can J Anaesth 1989; 36: 665-7.

22 Smith RM. Anaesthesia for Infants and Children, 4th ed. St. Louis: CV Mosby, 1980: 152. 